\title{
Evolución, situación actual y retos de la evaluación de políticas públicas en las Administraciones españolas (2000-2021)
}

\author{
Developments and challenges of public \\ policy evaluation in the Spanish administration \\ (2000-2021)
}

\author{
José María Casado \\ Eloísa del Pino \\ AIReF
}

\section{Resumen}

En este artículo se analiza la evolución de la evaluación de políticas públicas en las Administraciones central y autonómica españolas en las últimas dos décadas. En primer lugar, se explora la existencia en el caso de España de los elementos existentes en los países de nuestro entorno que más han avanzado en el proceso de institucionalización de la evaluación (marco normativo y organizativo, capacidad evaluadora y actitudes afines a la evaluación, y la práctica y uso de la evaluación). También se discute hasta qué punto los elementos que configuran nuestro sistema de evaluación logran garantizar los principios de independencia, investigación sistemática, profesionalidad y relevancia de los análisis que la literatura sobre institucionalización considera esenciales para el buen funcionamiento de los sistemas de evaluación.

Palabras clave: evaluación de políticas públicas, institucionalización, principios de la evaluación, España.

Clasificación JEL: C00, D6, D7, H1, H8.

\section{Abstract}

This article analyses the evolution of public policy evaluation in Spain between 2000 and 2021, at the central and regional levels. To do so, we first assess the presence in Spain of the elements that are present in countries that have made progress in the process of institutionalizing policy evaluation (a regulatory and organizational framework that supports evaluation, evaluation capacity and whether attitudes towards evaluation among policy makers, and whether evaluations are practiced and used). Secondly, we discuss the extent to which the elements that make up the Spanish evaluation system manage to guarantee the core principles (independence, systematic enquiry, professionalism and relevance of analysis) that the literature on institutionalization considers essential for the proper functioning of evaluation systems.

Keywords: public policy evaluation, institutionalization, core evaluation principles, Spain. 


\section{Introducción}

Los continuos avances y retrocesos experimentados en materia de evaluación en las últimas décadas en España han instalado entre los observadores cierto pesimismo, o al menos escepticismo, sobre la posibilidad de que las Administraciones españolas sean capaces de examinar de forma crítica y objetiva el impacto de la acción pública, repensar sus políticas y rendir cuentas a la ciudadanía. Desde entonces, se ha argumentado que nuestra Administración carece de los incentivos y de la capacidad interna suficiente para hacer evaluación de políticas públicas (en adelante, EVPP) o que no tiene cultura evaluadora. También se ha argumentado que, a pesar de que dispone de una gran cantidad de datos para hacer evaluación, es muy difícil acceder a ellos o que, cuando la evaluación se lleva a cabo, no se hace con el enfoque metodológico adecuado o no tiene la suficiente objetividad o trascendencia o, finalmente, que no se utiliza para mejorar las políticas y la eficacia y eficiencia del gasto público (Ruiz, 2012; Garde-Roca, 2006, 2017; De la Rica, 2020; Munárriz, 2020; FEDEA, 2021).

A pesar de esta percepción sobre las supuestas carencias de nuestro sistema, que teóricamente impedirían la consolidación de un sistema de EVPP en España, y, sin dudar de que la evaluación presenta todavía importantes desafíos, durante los últimos años, los distintos niveles de gobierno han puesto en marcha numerosas iniciativas y se ha desarrollado cierta actividad evaluadora.

En este artículo nos preguntamos cuál es la situación actual de la EVPP en España: hasta qué punto está justificada la preocupación de los expertos; en qué medida nuestro sistema se aleja del existente en otros países de nuestro entorno y de los elementos básicos que los especialistas identifican como necesarios para hablar de un sistema consolidado; $y$, finalmente, cuáles son los principales retos que afronta la EVPP para asegurarse su independencia, credibilidad y trascendencia.

Para responder a esta pregunta se propone el concepto de institucionalización de la EVPP y se analizan sus dimensiones para el caso de España. Se entiende por institucionalización «el proceso de incorporación de normas y rutinas al sistema institucional existente con el fin de estimular la demanda de evaluaciones por parte de la sociedad civil y de las propias autoridades y de garantizar tanto su práctica sistemática, independiente y profesional como su utilización por los responsables públicos en la adopción de decisiones» (AIReF, 2021, p. 28).

El concepto o, en realidad, los distintos conceptos de institucionalización han sido aplicados tanto para tratar de medir o analizar la situación de la EVPP en numerosos países en el mundo, incluida España, como para estimar en qué dimensiones es necesario fortalecer el sistema de EVPP existente en un país o región (por ejemplo, Jacob, Speer \& Furubo, 2015; Stockmann, Meyer \& Taube, 2020a, 2020b; Bustelo, 2020; AIReF, 2021). Este artículo busca contribuir a la literatura sobre institucionalización de la EVPP, discutiendo críticamente el propio concepto y aplicándolo al caso de España con evidencia sobre las Administraciones central y autonómica y su evolución entre 2000 y 2021. 
Como anticipo de las conclusiones, se puede sostener que, tras una etapa de incertidumbre, España ha realizado avances sustantivos en materia de evaluación en los últimos años. No obstante, y dado que nuestro país ya experimentó importantes retrocesos en el proceso de institucionalización de la EVPP, conviene consolidar estos avances antes de atreverse a confirmar que el sistema está ya maduro.

A partir de ahora, el artículo se organiza en otros tres epígrafes. En primer lugar, se revisa críticamente el concepto de institucionalización de la EVPP, se realiza una propuesta para su aplicación empírica, que incluye el análisis de los llamados principios de la evaluación. En segundo lugar, se repasan los avances y retrocesos del proceso de institucionalización en los niveles central y autonómico de gobierno en España para el periodo comprendido entre 2000 y 2021. Y finalmente, se discuten los hallazgos y los retos que afronta la EVPP en España.

\section{La institucionalización y los principios de evaluación: definiciones, dimensiones, limitaciones y propuesta para su aplicación empírica}

En las últimas décadas, la EVPP parece haber recibido un nuevo impulso en las democracias avanzadas. Junto a la presión que reciben los Gobiernos para mejorar la eficacia y eficiencia de crecientes volúmenes de gasto público y de profundizar en la calidad de las democracias a través de la transparencia, en los últimos años, el avance de las políticas informadas en la evidencia y el propio desarrollo de metodologías, tecnologías y la disponibilidad de datos, han impulsado la evaluación. Entendida como «la aplicación sistemática de procedimientos de las ciencias sociales para valorar la conceptualización, el diseño, la implementación y la utilidad de las intervenciones públicas» (Rossi, Freeman \& Lipsey, 2003, p.5), mediante la EVPP, las autoridades tratan de adoptar mejores decisiones, ser más transparentes, rendir cuentas sobre la utilización de los recursos públicos y su impacto y, también, en ocasiones, legitimar sus decisiones.

Sin embargo, ni todos los países ni dentro de ellos todas las organizaciones públicas muestran el mismo «activismo evaluador» (Pattyn, 2012). En muchos lugares la EVPP es una práctica poco normalizada e incluso esporádica. A veces, se lleva a cabo solo en un sector o en un organismo o depende de la voluntad de responsables públicos concretos, que durante un tiempo o en circunstancias específicas impulsan este ejercicio. Algunos Gobiernos se comprometen a evaluar determinadas políticas, debido a que esta es una exigencia para recibir fondos proporcionados por terceros o porque precisan revisar importantes programas de gasto o, en ocasiones, programas piloto específicos.

Más allá de algunos factores generales -por ejemplo, el ser o no una democracia, haber avanzado hacia el paradigma de la Nueva Gestión Pública o el pertenecer y/o recibir financiación procedente de instituciones terceras- (Del Pino \& Colino, 2021), no están claros los factores que contribuyen al surgimiento de la llamada $c a$ pacidad evaluadora, entendida como «la habilidad de asegurar recursos materiales, 
tecnología y profesionales para poder desarrollar evaluaciones creíbles e independientes de políticas, garantizar su utilización en la adopción de decisiones de política pública y en último término conseguir que se institucionalice» (AIReF, 2021).

Entre los expertos existe el convencimiento de que la calidad y la utilidad de la EVPP depende de la medida en que la capacidad evaluadora logre incardinarse en el engranaje institucional existente y perpetuarse en el tiempo, de modo que la práctica de la evaluación deje de ser un ejercicio aislado (Garde-Roca, 2006). Se pueden llevar a cabo mejores evaluaciones si, desde el origen de las políticas, se documentó el proceso de decisión identificando alternativas, si se especificó cuál era el estado ideal del problema al que se aspiraba, los objetivos a lograr, si se prepararon los sistemas de información o se establecieron los indicadores para medir la implementación y el impacto de la política. La trascendencia de la EVPP será mayor si está previsto que forme parte del proceso de rediseño de las políticas, si los evaluadores han acumulado suficiente experiencia para hacer participar a los evaluados e integrar sus necesidades y definir con ellos sus estrategias. Igualmente, la influencia de la EVPP será mayor si los responsables públicos se ven interpelados por la sociedad civil u otras autoridades para la utilización de sus resultados, con el fin de mejorar las intervenciones públicas.

Por ello, los expertos y numerosas organizaciones internacionales como Naciones Unidas (CEPAL, 2021), el Banco Mundial (Rist, Boily \& Martin, 2011), la OCDE (2021) o la Unión Europea (2007), o Lázaro (2015) han reflexionado sobre cómo caminar hacia la institucionalización de la EVPP. En la actualización del Atlas Internacional de la Evaluación de Furubo, Rist y Sandahl (2002), Jacob, Speer y Furubo (2015, pp. 10-11) analizan la situación de la institucionalización en 19 países a los que puntúan en nueve dimensiones e indicadores.

Por su parte, Meyer, Stockmann y Taube (2020, p. 15), en su intento reciente de definir y estimar de manera más completa el grado de institucionalización de la EVPP, sugieren comprobar la existencia de diferentes dimensiones en tres sistemas ${ }^{1}$ : el sistema político, el social y el profesional. En realidad, los autores formalizan la idea, presente en toda literatura sobre institucionalización, de que la consolidación de un sistema de evaluación de políticas implica no solo a las autoridades, sino también a la propia sociedad y a la comunidad profesional.

En su análisis de la evaluación en 17 países y en la Unión Europea, Stockmann, Meyer y Taube (2020a) pidieron a los expertos nacionales que analizan las características de diferentes dimensiones de la institucionalización, que trataran de identificar determinados indicios en los tres sistemas mencionados más arriba. En relación con el sistema político debían identificar en su país: 1) una política pública o estrategias de evaluación y de regulación general, o al menos sectorial, en la que se establezca la independencia, se regule la calidad de la evaluación, su orientación a medir el impacto, su presupuesto y se integre de algún modo en el Parlamento; 2) la práctica de la

1 Véase la discusión sobre el concepto y su vinculación con la sociología, la economía y la ciencia política en Meyer, Stockmann y Taube (2020, p. 8 y siguientes). 
evaluación, su frecuencia en diferentes sectores de política, los determinantes de la evaluación, el tipo de evaluación que se practica, su naturaleza interna o externa y si existe o no un organismo evaluador; y 3) hasta qué punto, quién, para qué y por qué se usa la evaluación, en qué sectores se utiliza más y con qué mecanismos se garantiza su uso.

Por lo que se refiere al sistema profesional, deberían identificarse: 1) formación de educación superior; 2) publicaciones científicas y técnicas, guías, plataformas de comunicación, organizaciones profesionales, un mercado para la evaluación y la profesión de evaluador; y 3 ) estándares y reglas desarrolladas por estos profesionales, exigidas por los propios clientes y seguidas por los evaluadores.

En lo que respecta al sistema social, se avanza en el proceso de institucionalización: 1) si es usual en el país que las evaluaciones se utilicen para informar las decisiones o los procesos participativos; si se utiliza por parte de la sociedad civil, individuos, empresas u organizaciones del tercer sector; si la sociedad participa en las evaluaciones; 2) si la sociedad conoce y entiende el significado de la evaluación, si los informes se publican y discuten en los medios; y 3) si existe una demanda de evaluación hacia los decisores públicos procedente de la sociedad civil.

Meyer, Stockmann y Taube (2020) no incluyen ninguna mención directa a la cultura evaluadora como tal, que otros autores consideran un ingrediente esencial para la institucionalización. Sin embargo, resulta plausible que para que la evaluación pueda finalmente institucionalizarse, sea necesario que la sociedad civil y los responsables públicos compartan ciertas actitudes hacia la misma. La cultura evaluadora podría definirse como «un patrón de creencias, valores y conocimientos básicos compartidos por los responsables de las distintas fases del ciclo de las políticas que les proporcionan normas de comportamiento en relación con la demanda, la práctica, la utilización y difusión de las evaluaciones y la promoción y participación de la sociedad en este proceso» (definición adaptada de De Peuter \& Pattyn, 2009, p. 6).

A pesar de la larga enumeración de diferentes dimensiones que indicarían el grado de institucionalización de la EVPP, se sabe poco sobre qué elementos concretos hacen que los sistemas de evaluación sean exitosos y más bien parece que pueden encontrarse distintos modelos eficaces en distintos contextos. Por ejemplo, Rosentein (2015) examina lo que llama el estatus de la Política Nacional de Evaluación en 115 países. De ellos, solo 20 tienen una norma en la que se recoge la política de evaluación. Algunos realizan evaluación de modo rutinario, a pesar de no tener una norma. Al mismo tiempo, la evaluación estaba a cargo de diferentes tipos de organismos que pueden ser igualmente eficaces, a pesar de sus diferencias institucionales. En definitiva, ni la existencia de una norma ni la centralización de la evaluación en un solo organismo parecen elementos necesarios para la institucionalización de la EVPP.

Asimismo, un reciente estudio de la OCDE (2021), realizado a instancias de la $\mathrm{AIReF}^{2}$, muestra que los países que han avanzado en la institucionalización de la evaluación comparten algunas similitudes respecto a sus sistemas de evaluación,

\footnotetext{
${ }^{2}$ Este estudio ha sido financiado y ha contado con la supervisión técnica de la Comisión Europea (DG REFORM).
} 
pero también diferencias. En algunos lugares no se puede mencionar una agencia concreta que practique la EVPP. La evaluación se lleva a cabo por centros gestores de la propia Administración con funciones de evaluación y, en ocasiones, estas evaluaciones se coordinan por un organismo. En otros lugares, existen instituciones independientes evaluadoras. Además, los departamentos de Hacienda suelen jugar un papel relevante en lo que se refiere a la integración de los resultados de las evaluaciones en el ciclo presupuestario. Un elemento común destacable es la existencia de múltiples iniciativas para mejorar la disponibilidad de datos, la actualización periódica de los sistemas de información, su interconexión y el establecimiento de las condiciones para su utilización. También exhiben importantes diferencias respecto a la existencia de normas, el grado de centralización de estas tareas dentro de sus Gobiernos centrales o el papel de los Parlamentos en el sistema.

Dados estos hallazgos, más que tratar de identificar fórmulas normativas o fórmulas organizativas específicas, parece más útil pensar en cómo cada país, teniendo en cuenta sus peculiaridades político-administrativas y socioeconómicas, puede garantizar que su sistema de evaluación asegure una serie de principios que se predican de los sistemas de evaluación exitosos. Por ejemplo, el Banco Mundial (2019) ha sugerido que estos principios pueden resumirse en credibilidad, utilización e independencia. La propia AIReF (2021) ha enumerado los siguientes, que guían el desarrollo de su actividad evaluadora: la investigación sistemática, entendida como la realización de un análisis riguroso de datos relevantes, utilizando las metodologías más apropiadas que provean de evidencias objetivas y factuales a sus evaluaciones y sobre las que se sustenten las propuestas y recomendaciones; la independencia, definida como la ausencia de conflictos de interés entre los evaluadores y de presión política u organizativa, así como la autonomía en la realización de las evaluaciones y en la difusión de los resultados; la profesionalidad de los equipos, que poseerán los conocimientos y habilidades necesarios para evaluar y mantener la integridad del proceso, incluyendo en él la participación de los evaluados; la relevancia o transcendencia de los análisis, seleccionando programas a evaluar en función de su importancia social o presupuestaria y facilitando la utilización de sus resultados.

En resumen, para explorar hasta qué punto los sistemas de EVPP están institucionalizados, proponemos, en primer lugar, analizar el grado de desarrollo de una serie de elementos que aparecen en los sistemas de evaluación más reconocidos y que están relacionados: comprobar si existe un marco regulatorio y una estructura organizativa que pueda amparar el desarrollo de la evaluación, la capacidad evaluadora y valores afines a la evaluación; y, por último, si hay una actividad evaluadora sostenida y el fruto de las mismas se utiliza. En segundo lugar, proponemos analizar hasta qué punto estos elementos logran garantizar los principios de evaluación. A continuación, aplicamos esta propuesta al análisis del caso de España. 


\section{La evaluación de políticas en España a partir del año 2000}

\subsection{Antecedentes: de la pertenencia europea a la extinción de la AEVAL}

Hasta los años 2000, España no inicia un proceso deliberado de construcción de un sistema de evaluación integral. Entre los años 1980 y 1990, las evaluaciones que se habían llevado a cabo se concentraron en determinados sectores de política pública (educación, empleo, servicios sociales, sanidad, fondos europeos o cooperación al desarrollo) y se realizaban de forma aislada (Fenstein \& Zapico-Goñi, 2010; Bustelo, 2020). Como es bien conocido, España es uno de los países lentos en cuanto a la implantación de la Nueva Gestión Pública, debido a razones institucionales y de cultura político-administrativa (Pollitt \& Bouckaert, 2017). Ello puede explicar cierto retraso respecto a otros países en el despegue de la evaluación, situación que empieza a corregirse a partir del ingreso en la UE, una de las razones de su puesta en marcha en los primeros años 2000.

\subsubsection{El marco organizativo y normativo}

En la primera década de 2000, el paso más significativo en materia de evaluación fue la creación de la Agencia Estatal de Evaluación de las Políticas Públicas y Calidad de los Servicios (AEVAL), en la Ley 28/2006 de Agencias Estatales. Se reguló mediante el RD 1418/2006, por el que se aprueba su Estatuto. La Agencia estaba vinculada al ejecutivo y su presidente era nombrado por el Gobierno. Los encargos de evaluación se recogían en Acuerdo del Consejo de Ministros a propuesta de la Agencia, que debía ser aprobada por el pleno de su Consejo Rector. Además, varias previsiones legales incluían mandatos de evaluación adicionales de programas recogidos en el Programa Nacional de Reformas y en la Estrategia de Desarrollo Sostenible.

Tras una primera década de crecimiento en la que realizó múltiples evaluaciones, la AEVAL fue perdiendo su impulso inicial. A partir de 2011, muchas de las demandas hacia la AEVAL estuvieron más relacionadas con la consultoría de gestión pública que con la propia evaluación, en parte explicado porque estaba en marcha la Comisión para la Reforma de las Administraciones públicas (CORA) ${ }^{3}$.

En 2017, en un contexto de racionalización del sector público, la AEVAL se disolvió y se creó en su sustitución el Instituto para la Evaluación de Políticas Públicas (IEPP) con rango de subdirección general adscrita a la Secretaría de Estado de Función Pública ${ }^{4}$.

${ }^{3}$ La CORA, creada en 2012 en el contexto de la Gran Recesión, tenía por objeto eliminar duplicidades y reforzar los mecanismos de cooperación entre Administraciones, avanzar en la simplificación administrativa, identificar las actividades de gestión en las que pudieran optimizarse el uso de los recursos públicos y revisar el número de entes en las Administraciones.

${ }^{4}$ Artículo 13.7 y la disposición adicional novena Real Decreto 769/2017.

https:/www.boe.es/buscar/pdf/2017/BOE-A-2017-9012-consolidado.pdf 


\subsubsection{Capacidad evaluadora y cultura de evaluación}

Si se compara con otros países, la AEVAL era una Agencia pequeña. Aunque llegó a tener 59 efectivos en 2009, siempre estuvo lejos de su dotación potencial (75 efectivos para ese año) y fue poco a poco perdiendo personal. En 2016, un año antes de su desaparición, contaba con 38 personas (AEVAL, 2018). Además, solo una parte reducida de su personal, menos de la mitad, se dedicaba a la EVPP.

La AEVAL contaba sobre todo con personal funcionario, lo cual pudo ser una limitación dada la falta de experiencia en la Administración pública española en la evaluación de políticas. Además, la Agencia apostó siempre por realizar sus propias evaluaciones, sin contar con medios externos. A las limitaciones de personal, se le unieron las restricciones de acceso a datos a las que se enfrenta tradicionalmente la evaluación de políticas públicas, la llegada de la crisis y otras razones de tipo político.

\subsubsection{La actividad evaluadora y la trascendencia de las evaluaciones}

Aunque la AEVAL no era la única institución encargada de realizar evaluaciones, sí era sin duda la principal en esos años. La división de evaluación de la AEVAL llevó a cabo alrededor de 41 evaluaciones, dos de ellas para las comunidades autónomas (CC. AA.), y elaboró algunas propuestas metodológicas, programas de formación ${ }^{5}$ y cuatro guías ${ }^{6}$.

Respecto a sus relaciones, la AEVAL coordinaba la Red Interadministrativa de Calidad de Servicios Públicos, en la que participaban las CC. AA. y la Federación Española de Municipios y Provincias (FEMP) y en cuyo seno había un Comité de Evaluación de Políticas Públicas. Además, participaba en la Red Europea de Administración Pública (EUPAN) con el resto de los países de la Unión Europea. En cuanto a sus vínculos con la sociedad civil, la AEVAL integró en su Consejo Rector a distintos académicos relacionados con las políticas públicas y colaboraba con la Sociedad Española de Evaluación.

Hubo también otros organismos que realizaron sus propias evaluaciones. Un estudio encargado por AEVAL a la Universidad Carlos III sobre la Evaluación de Políticas y Programas Públicos en la Administración General del Estado (2007-2011) identificó 71 evaluaciones «en sentido estricto» o «verdaderas» ${ }^{7}$. Casi la mitad, 34, habían sido llevadas a cabo por la AEVAL, 18 por la Dirección General de Planificación y Evaluación para el Desarrollo en el Ministerio de Asuntos Exteriores y Cooperación, 6 por parte del Ministerio del Medio Ambiente y Medio Rural y

${ }^{5}$ Véase el Eje Estratégico II: la promoción de la cultura de la evaluación (Informe General de Actuación de AEVAL 2016, 2018).

${ }^{6}$ Además de ellos, la división de calidad de los servicios elaboró 24 informes más y varias guías. Esta división realizaba también otras tareas de consultoría administrativa (certificaciones de evaluaciones organizativas o formación, entre otras).

${ }^{7}$ Según Stufflebeam y Shinkfield (1995) las evaluaciones verdaderas son los procesos que, a partir de la investigación sistemática, proporcionan evidencia sólida sobre políticas, programas o planes públicos e incorporan un juicio de valor sobre la base de criterios explícitos o implícitos y orientaciones prácticas en relación con la intervención evaluada. 
Marino, 5 por la Fundación Tripartita para la Formación en el Empleo, 3 por el Centro para el Desarrollo Tecnológico Industrial y otras organizaciones (Ruiz, 2012). De entre todas las evaluaciones, solo una fue ex ante.

Para acabar el repaso al periodo comprendido entre 2000 y 2017 y poder concretar el grado de institucionalización de la evaluación en España en esos años, cabe mencionar varios análisis sobre institucionalización de la EVPP que incluyeron el caso de España. El estudio de Jacob, Speer \& Furubo (2015) establece distintos grados de madurez en relación con la evaluación de políticas en función de la posición de cada país en nueve dimensiones. España, junto a Irlanda, Italia y Nueva Zelanda, se ubica entre los países con un grado de madurez medio. Por su parte, Stockmann, Meyer \& Taube (2020b) elaboraron un índice para analizar el grado de institucionalización de los países. Se aplica a las diferentes dimensiones de la institucionalización que identificaron en su marco conceptual anteriormente mencionado. De acuerdo con este, Suiza estaba claramente por encima de los demás países en los tres sistemas que los autores analizan (político, social y profesional), mientras que Rumanía, Portugal, Polonia, Letonia e Irlanda, se situaban por debajo de la media también en los tres. Por su parte, Alemania, Dinamarca y Finlandia consiguieron situarse por encima de la media en dos de los sistemas, mientras que otros países, entre ellos España, Reino Unido, Italia, Bélgica y la República Checa, lo hacen al menos en uno de ellos (Figura 1), por lo que, de acuerdo con ese estudio, se podría concluir que España posee un grado de institucionalización de la evaluación medio-bajo.

\section{FIGURA 1}

\section{LA INSTITUCIONALIZACIÓN DE LA EVALUACIÓN DE POLÍTICAS EN PAÍSES SELECCIONADOS}

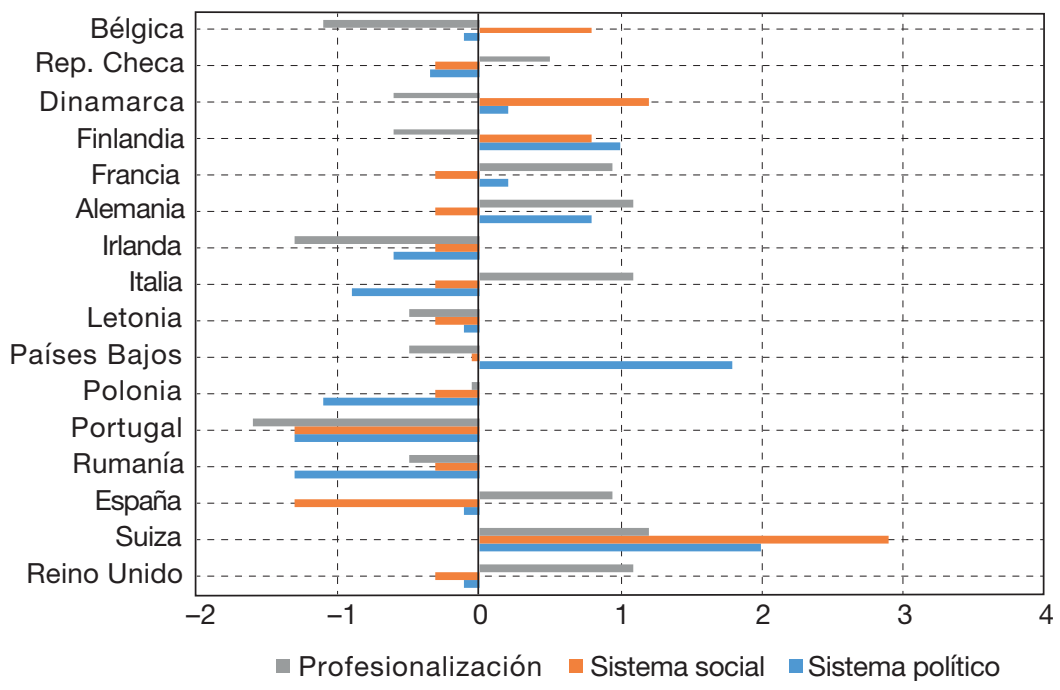

FUENTE: Stockmann, Meyer y Taube (2020b, p. 513). Z-Scores de los índices estandarizados de los sistemas político, social y profesional. 
Aunque estos análisis son sin duda interesantes, ninguno de ellos incluye las últimas e importantes iniciativas en materia de EVPP que han tenido lugar en España ni contienen una referencia sistemática a la situación de la evaluación en las CC. AA. En el próximo epígrafe se intenta resolver esta limitación, utilizando el mismo esquema empleado en esta sección para analizar los avances ocurridos en esta materia en España desde 2017 hasta el otoño de 2021.

\subsection{El reciente impulso a la evaluación de políticas públicas en la Administración} General del Estado (2017 a 2021): la experiencia de la AIReF

\subsubsection{Marco organizativo y normativo}

La Autoridad Independiente de Responsabilidad Fiscal (AIReF), que en principio no tenía previsto desempeñar la función evaluadora de políticas, ha tenido un protagonismo creciente en los últimos años. La AIReF se crea con la Ley Orgánica de Estabilidad Presupuestaria de 2013. Su origen tiene lugar, al igual que la mayoría de las instituciones fiscales independientes, como respuesta a la crisis de 2008 para el refuerzo de la estabilidad presupuestaria. Su actividad está regulada en su propio Estatuto Orgánico, aprobado por RD 215/2014, de 28 de marzo y su independencia se garantiza por, entre otros mecanismos, su forma de financiación mediante una tasa, su origen y vinculación con Europa, el modo en que se realizan sus encargos con mayor alcance que el de una legislatura, y el modo de selección de su presidente (en la actualidad presidenta), que requiere la mayoría absoluta del Parlamento y se realiza fuera del ciclo político.

Después de alguna experiencia inicial de la AIReF en materia de evaluación por encargo de las CC. AA., el Gobierno central solicitó a la AIReF en 2017 la evaluación de diversos capítulos del gasto público en varios años, fases y etapas. Este encargo supuso el impulso definitivo a la actividad de EVPP para este organismo, aunque no era ajena en instituciones similares en los países de nuestro entorno (Herrero, 2021). Desde ese momento, la evaluación en la AIReF se regula mediante acuerdos del Consejo de Ministros conocidos como Spending Reviews (SR) o solicitudes de evaluación del gasto que el Gobierno central hace a la AIReF en políticas sectoriales de competencia exclusiva o compartida. Una vez recibidos los encargos, de periodicidad anual, AIReF elabora para cada uno un plan de acción donde detalla el contexto, objetivos, ejes, metodologías, bases de datos, gobernanza, publicidad, calendario y presupuesto de las evaluaciones. Estos planes de acción tienen que ser ratificados por el Consejo de Ministros. Además de los encargos de la Administración central, la AIReF también realiza evaluaciones para los Gobiernos autonómicos y locales, habiéndose multiplicado exponencialmente sus estudios para estos niveles de gobierno en los últimos años.

Además de la AIReF, en la Administración central existen otros organismos que realizan evaluaciones o realizan algunas tareas vinculadas a la evaluación. En 2020, nuevamente, el RD 307/2020 adscribió el IEPP a la Secretaría de Estado de Política 
Territorial y Función Pública, manteniendo su rango de subdirección general. Adicionalmente, algunos centros gestores realizan evaluaciones internamente o con la ayuda de terceros (Instituto de Evaluación de Políticas Públicas, 2021). Estas evaluaciones, en ocasiones, forman parte de planes plurianuales de evaluación. Por poner algunos ejemplos, la cooperación española cuenta con una política de evaluación, un plan bienal de evaluaciones y una metodología de evaluación ${ }^{8}$. También existe un plan anual de evaluación de la formación del Servicio Público de Empleo. La evaluación de este sistema está regulada en la ley 30/2015 ${ }^{9}$. En el Ministerio de Trabajo y Economía Social existe un Plan Estratégico Nacional del Fondo Social Europeo ${ }^{10}$. Igualmente, en el caso del Ministerio de Hacienda y Función Pública se dispone de un Plan de Evaluación de los Programas Operativos FEDER ${ }^{11}$.

La normativa nacional prevé también varios organismos o dispositivos sectoriales que realizan algún tipo de evaluación, aunque es cierto que no siempre realizan EVPP en sentido estricto. En el ámbito de la educación y la ciencia, pueden mencionarse el Instituto de Evaluación, la Agencia Nacional de Evaluación de la Calidad y Acreditación (ANECA), la cual evalúa el contenido de las titulaciones universitarias o del perfil del profesorado, o el Sistema Unificado de Evaluación de Investigación, Desarrollo e Innovación. En Sanidad, la Red Española de Agencias de Evaluación de Tecnologías Sanitarias y Prestaciones del Sistema Nacional de Salud también lleva a cabo evaluaciones. Cabe destacar también al Instituto de Estudios Fiscales.

Con todo, el propio Plan de Recuperación, Transformación y Resiliencia (PRTR) presentado por el Gobierno de España en mayo de 2021, con el objetivo de aprovechar los nuevos instrumentos comunitarios de financiación denominados Next Generation EU, puestos en marcha en el contexto de la COVID-19, ha considerado que la evaluación necesita un apoyo mayor. El PRTR menciona la EVPP en varios de los denominados componentes, en concreto en el 11 (Modernización de las Administraciones públicas) y en el 29 (Mejora de la eficacia del gasto público) $\mathrm{y}$, en particular, consolida el papel que tendrá AIReF como organismo evaluador reforzando su independencia, profesionalidad, sistematicidad y la relevancia de sus evaluaciones ${ }^{12}$.

Además, desde un punto de vista normativo, en la Administración del Estado, en verano de 2021, finalizó el plazo de consulta pública sobre el Anteproyecto de ley de institucionalización de la EVPP en la Administración General del Estado, cuyo

\footnotetext{
8 http://www.exteriores.gob.es/Portal/es/SalaDePrensa/Multimedia/Publicaciones/Documents/ Cooperacion/Evaluacion/Metodologias/Metodologiade\%20evaluaci\%C3\%B3n\%20\%20de\%201a\%20 Cooperaci\%C3\%B3n\%20Espa\%C3\%B1ola\%20I\%20completo.pdf

${ }_{9}$ https://www.sistemanacionalempleo.es/evaluacion_formacion.html

${ }^{10} \mathrm{https}: / /$ www.mites.gob.es/uafse/es/evaluaciones/index.htm En la página se pueden encontrar también las evaluaciones para todas las CC. AA.

${ }^{11}$ https://www.dgfc.sepg.hacienda.gob.es/sitios/dgfc/es-ES/ipr/fcp1420/e/PEF1420/Documents/ Plan_de_Evalaucion_Comun_FEDER_v14.pdf

${ }_{12}$ Véase el PRTS https://www.lamoncloa.gob.es/temas/fondos-recuperacion/Documents/ 30042021-Plan_Recuperacion_\%20Transformacion_\%20Resiliencia.pdf
} 
objetivo era el de «impulsar la institucionalización y conformar un sistema más robusto de evaluación» por parte del Ministerio de Hacienda y Función Pública ${ }^{13}$.

\subsubsection{Capacidad evaluadora y cultura de evaluación}

El presupuesto público dedicado a evaluación es creciente, pero las Administraciones se siguen viendo limitadas por otros aspectos que condicionan su capacidad de evaluar. En cuanto a la disponibilidad de efectivos para llevar a cabo las tareas de evaluación, en el caso del IEPP, su Relación de Puestos de Trabajo (RPT) incluye once efectivos. Por su parte, en AIReF, el personal dedicado a la evaluación es escaso, sin sobrepasar en la actualidad la decena de efectivos (con perfiles de economía, matemáticas, estadística y ciencia política). Aunque AIReF asume en solitario una parte de las evaluaciones que realiza, para otras, cuenta con medios externos. Pero, incluso en este último caso, el volumen de trabajo es grande debido a que la AIReF diseña, dirige y coordina sus evaluaciones y se involucra intensamente en el proceso de evaluación mediante la configuración de equipos mixtos con terceros actores. Esta práctica permite al propio organismo aprender de cada evaluación, además de contribuir a generar un mercado de evaluación (en universidades y el sector privado), lo cual es importante para que se pueda hablar de institucionalización de la evaluación en un país, tal y como se ha señalado anteriormente.

Por su parte, existen varias iniciativas sobre evaluación en la sociedad civil, aunque aún son excepcionales en España. En la academia, algunos programas de grado y postgrado incluyen asignaturas de evaluación de políticas, por ejemplo, las carreras de Economía o Ciencias Políticas de algunas facultades, siendo también común en másteres en gestión y Administración pública. Por lo que se refiere a otras iniciativas no estrictamente académicas, cabe destacar nuevas redes que integran a expertos y académicos con capacidades cuantitativas y cualitativas para realizar evaluaciones ${ }^{14}$. Además, existen organizaciones con larga tradición como la Sociedad Española de Evaluación de Políticas y la Asociación Ibérica de Profesionales por la Evaluación (APROEVAL). Estas asociaciones y sus miembros participan activamente en reuniones científicas nacionales e interacciones dedicadas a la difusión de la evaluación de políticas o donde la evaluación ocupa algún tipo de espacio. En la propia Administración, el Grupo de Referencia en Evaluación de la Administración General del Estado se reúne mensualmente. Quizá en un futuro cercano se podrá hablar de un mercado interno de evaluación, en el que distintos organismos de las Administraciones se especialicen en distintos tipos de evaluación sectorial.

En la Administración central, el PRTR (p. 172) ha puesto de manifiesto el propósito de apoyar la función evaluadora de la AIReF dada la creciente demanda

13 Este Anteproyecto de ley puede consultarse aquí: https://www.mptfp.gob.es/portal/ministerio/ participacion_proyectos/consulta_previa/proyectos/2021/2021-05-17.html

14 Por ejemplo, la Red por las Buenas Prácticas en Evaluación (RedEV), integrada por cuatro organizaciones (Afi, Iseak, Ivie y Ksnet). 
mediante «el refuerzo de la capacidad del evaluador a través de la creación de una división permanente de evaluación en el seno de la AIReF para dar continuidad y permanencia a los ejercicios de Spending Review». La División de Evaluación del Gasto Público se ha creado en septiembre de 2021, consolidando así, en la estructura de la AIReF, una función que ya venía realizándose.

En relación también con la capacidad, uno de los asuntos que más se han discutido en los últimos años ha sido la disponibilidad de datos para la realización de las evaluaciones. En este sentido, la AIReF propuso el diseño de una estrategia nacional para avanzar en la disponibilidad de datos administrativos convenientemente anonimizados, para ponerlos a disposición de las Administraciones y de la academia en general $^{15}$, que fue compartida también por la comunidad científica e investigadora (Almunia \& Rey-Biel, 2020).

\subsubsection{La actividad evaluadora y la trascendencia de las evaluaciones: nuevos avances a raíz del PRTR}

La ausencia de un observatorio que recoja evaluaciones y recomendaciones, convierte en muy difícil la tarea de realizar un seguimiento exhaustivo de la actividad evaluadora de decenas de estos organismos y de la utilización de estos análisis ${ }^{16}$.

Entre 2017 y 2020, la actividad del IEPP ha sido limitada, realizando una evaluación y cuatro guías ${ }^{17}$. En cuanto a la AIReF, en 2017, el Gobierno de España encargó a este organismo la revisión integral del gasto público (el ya mencionado aquí SR). Este ejercicio, con una duración prevista de tres años, se ha concretado en tres encargos (Cuadro 1). En el marco del SR, las evaluaciones solicitadas por la Administración General del Estado se han referido a importantes capítulos de gasto y suponen algo más de 75.330 millones de euros (alrededor de un 15\% del gasto público total). Entre los sectores analizados se encuentran subvenciones, sanidad, beneficios fiscales, empleo, becas, I+D, industria, infraestructuras, correos y telégrafos, o lucha contra la pobreza. El catálogo de políticas a evaluar para la Administración central se ha ampliado con la tercera fase del SR, que incluye las líneas de préstamos, ayudas e instrumentos financieros al tejido empresarial por parte de las entidades públicas y la gestión de residuos, así como un estudio de evaluación relativo a la cooperación financiera internacional y, en particular, del Fondo para la Promoción del Desarrollo (FONPRODE), encargado también a la AIReF por el Consejo de Ministros.

15 Véase la Opinión para una estrategia de acceso a datos administrativos. https://www.airef.es/es/opiniones/estrategia-acceso-datos-administrativos/

${ }^{16}$ En varias de las direcciones web de los organismos mencionados en el epígrafe anterior pueden encontrarse los informes de evaluación, en algunos casos uno al año.

${ }_{17}$ Véanse los informes del IEPP en https://www.mptfp.gob.es/portal/funcionpublica/ evaluacion-politicas-publicas/Informes-de-Evaluacion.html 
A lo largo de este tiempo, los Gobiernos autonómicos y un ayuntamiento han solicitado a la AIReF diferentes evaluaciones en diversos sectores de política de gran relevancia como la sanidad, la educación, o el empleo.

En total, desde 2017 y hasta el momento, la AIReF ha realizado tanto para el Gobierno central como para nueve comunidades autónomas, quince evaluaciones. Están en curso otras once y varias más se encuentran en el proceso de solicitud (Cuadro 1).

\section{CUADRO 1}

\section{EVALUACIONES COMPLETADAS POR LA AIREF O EN FASE DE DESARROLLO POR ENCARGO DEL GOBIERNO CENTRAL Y DE LAS COMUNIDADES AUTÓNOMAS}

\section{ENCARGO PLURIANUAL DEL GOBIERNO CENTRAL: SPENDING REVIEW}

\section{Fase 1. Spending Review (2018-2019)}

Evaluación de estrategia y procedimiento

en la concesión de subvenciones

Medicamentos dispensados a través de receta médica

Políticas activas de empleo

Becas de educación universitaria

Promoción de talento y empleabilidad en $\mathrm{I}+\mathrm{D}+\mathrm{i}$

Fortalecimiento de la competitividad empresarial

Sociedad Estatal Correos yTelégrafos
Fase 2. Spending Review (2019-2020)

Beneficios fiscales

Gasto hospitalario del SNS: farmacia e inversión en bienes de equipo

Incentivos a la contratación y al trabajo autónomo

Infraestructuras de transporte

Fase 3. Spending Review (2021-)

íneas de préstamos, ayudas e instrumentos financieros al tejido empresarial por entidades públicas

Gestión de los residuos urbanos

\section{OTROS ENCARGOS DEL GOBIERNO CENTRAL}

Estudio sobre Renta Mínima, Ingreso Mínimo Vital, Fondo para la Promoción del Desarrollo FONPRODE

Sanidad: farmacia hospitalaria, extrahospitalaria, sociosanitaria, inversión alta tecnología, sistemas información recursos humanos, determinantes gasto

Políticas activas de empleo: orientación, incentivos, formación, inserción, itinerarios, etc.

Educación: universidades y no universitaria, gobernanza, actividad productiva, financiación, recursos humanos

Política industrial

Institucionalización de la evaluación: diagnóstico y propuestas

Publicidad institucional, gobernanza y planificación, transferencias de valor a los medios, transparencia

Estudio sobre empresas y fundaciones públicas autonómicas

Concesiones para la construcción y explotación de infraestructuras

FUENTE: Elaboración propia. 
Además, en 2021, el PRTR ha incluido un hito de gran importancia para la consolidación del proceso de evaluación del gasto en España planteando un nuevo proceso de Spending Review para un período de cinco años (2022-2026). Este periodo pone de manifiesto la intención de separar el proceso de evaluación de las legislaturas.

Tan importante como realizar las evaluaciones es asegurar su utilización para lo que, incluso en los sectores donde la EVPP cuenta con más tradición, como la cooperación al desarrollo, este sigue siendo un reto pendiente (Gudiño, 2015). El propio PRTR (p. 133) prevé algunas reformas tomando como referencia los resultados de las evaluaciones de AIReF en el ámbito de las políticas activas de empleo, la simplificación y racionalización de los incentivos a la contratación o los beneficios fiscales. Otras evaluaciones de AIReF han contribuido a la configuración de distintas medidas de política pública en industria, fiscalidad, sanidad o universidades, o en relación con el Ingreso Mínimo Vital.

También vinculado a garantizar el uso de las evaluaciones, otro importante hito recogido en el PRTR es la previsión de creación de una unidad técnica en el Ministerio de Hacienda para el seguimiento de las propuestas de la AIReF. Se avanzará así en la implementación del principio de «cumplir o explicar», según el cual las Administraciones deben al menos estudiar las propuestas de la AIReF y razonar su no-aplicación. También debe destacarse la propuesta que incluye el PRTR, consistente en que las evaluaciones sean llevadas a las conferencias sectoriales donde se reúnen cada ministerio y las consejerías del ramo. Además, se prevé que, antes del 31 de marzo de cada año, el Ministerio de Hacienda remita al Consejo de Ministros un informe con el estado de las recomendaciones. La Figura 2 resume la arquitectura institucional que, de aplicarse las medidas contenidas el PRTR, involucrará a la AIReF con otras instituciones del Estado y, por tanto, supondrá un paso importante para la institucionalización de la evaluación.

FIGURA 2

\section{LA ARQUITECTURA INSTITUCIONAL EN MATERIA DE EVALUACIÓN PREVISTA EN EL PRTR (2021)}

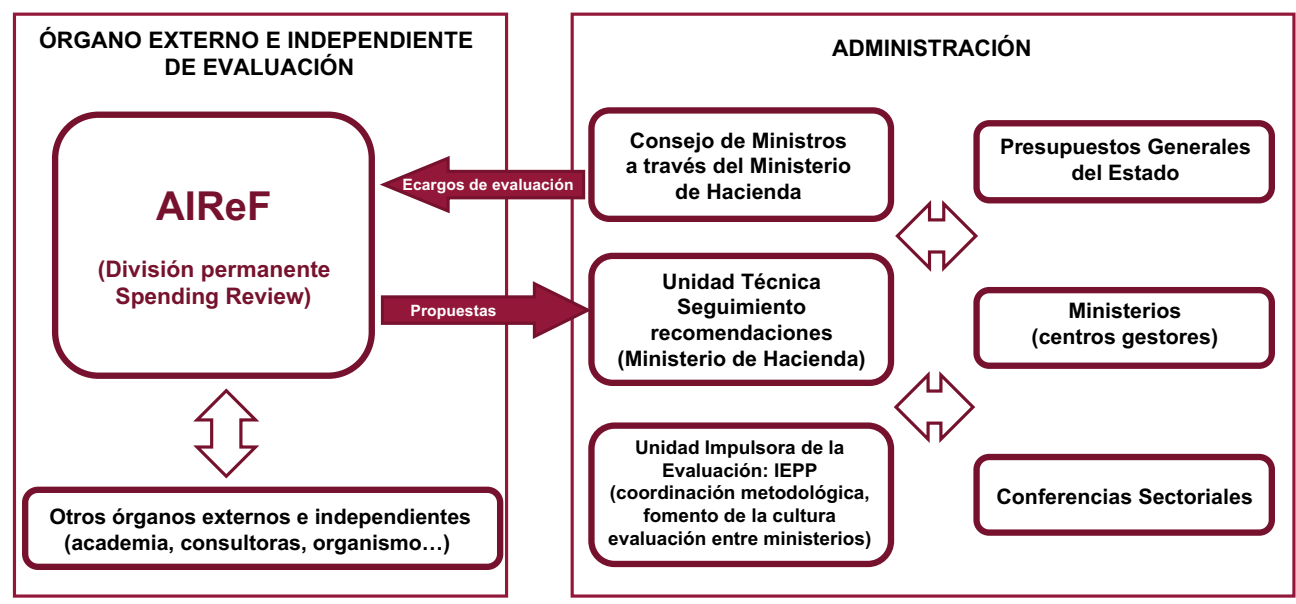

FUENTE: Elaboración propia. 
Finalmente, de cara a garantizar la trascendencia de las evaluaciones, se ha aprobado la Orden del Ministerio de Hacienda en la que se establecen las normas para la elaboración de los Presupuestos Generales del Estado para 2022. En ella se determina que los resultados de los procesos de evaluación del gasto público serán tenidos en cuenta a partir de ahora en la discusión presupuestaria y, para ello, la Dirección General de Presupuestos podrá recabar la información que requiera a los centros gestores de los distintos ministerios.

\subsection{La evaluación de políticas públicas en las comunidades autónomas (2005 a 2021)}

\subsubsection{Marco organizativo y normativo}

Las CC. AA. también han reforzado sus marcos legales y organizativos para evaluar las políticas. Aunque existen una gran variedad de situaciones que se expresan en la distinta plasmación normativa y que, en la mayoría de los casos, se circunscribe a reforzar la evaluación para el seguimiento de las políticas dentro de los centros gestores de ámbito sectorial.

Navarra cuenta con la Ley Foral 21/2005 de Evaluación de Políticas Públicas y Calidad de los Servicios. Esta ley, promulgada antes de la creación de la AEVAL, contiene una regulación detallada que declara la voluntad de constituir y desarrollar un sistema público de evaluación y establece que cada organismo podrá acordar autónomamente la evaluación de sus políticas.

Sin disponer de una ley, otras CC. AA. dedican parte del articulado de algunas de sus normas a la EVPP. En Aragón, la Ley 5/2017 de Integridad y Ética Públicas, completa las referencias a la evaluación que ya hacía su Ley 5/2013 de Calidad de los Servicios, estableciendo quién será el organismo evaluador (Agencia de Integridad y Ética Públicas), los principios de evaluación y la rendición de cuentas debida a las Cortes de Aragón. En Cataluña, la Ley 5/2020 de medidas fiscales, financieras, administrativas y del sector público, añade un capítulo al texto refundido de su Ley de Finanzas Públicas en el que define la EVPP, los criterios de evaluación y sus objetivos, así como el proceso de evaluación en el que participarán el departamento competente en materia de finanzas públicas y los centros directivos, que deberán realizar planes de evaluación plurianuales de las políticas que hayan diseñado. En Galicia, el Decreto 97/2020 regula determinados instrumentos para la gestión, evaluación, supervisión y mejora de la calidad en el sector público autonómico y regula las modalidades de lo que denomina evaluación de la calidad de las políticas públicas. Castilla y León también cuenta con varias normas pero, como demostró la reciente evaluación de AIReF sobre este tema en la comunidad autónoma, no están implementadas hasta el momento (AIReF, 2021).

La Junta de Andalucía trabaja en la Ley de Organización y Funcionamiento del Sistema de Evaluación de Políticas Públicas para establecer el marco organizativo 
necesario para la evaluación y regular su funcionamiento e interrelación entre las fases del ciclo de las políticas, así como la participación ciudadana en cada etapa. El Plan Estratégico de Gobernanza e Innovación Pública 2020 del País Vasco prevé la implantación del Sistema de Evaluación de las Intervenciones Públicas.

Estas, y gran parte del resto de las CC. AA., incluyen referencias a la EVPP en las leyes de transparencia, de participación o Gobierno Abierto que han sido aprobadas desde 2011. Sin embargo, en la mayoría de las ocasiones se trata de menciones generales como, por ejemplo, al derecho de los ciudadanos a participar en las evaluaciones de las políticas. Por otro lado, en todas las CC. AA. existe regulación sectorial que realiza previsiones sobre la EVPP, por ejemplo, es habitual en la normativa de políticas activas de empleo, de protección ambiental, en las políticas sanitarias, educativas, de género, de servicios sociales o en las políticas de transparencia.

Por lo que se refiere a la estructura organizativa de la evaluación en las CC. AA., la situación también es diversa. Existen pocas agencias generalistas, siendo el caso de Iválua en Cataluña el más conocido. Este consorcio creado en 2006 está formado por la Generalitat, la Diputación de Barcelona y la Universidad Pompeu Fabra. En 2019, Navarra estableció que el Observatorio de la Realidad Social ejercerá la planificación y la evaluación de las políticas de servicios sociales y empleo, así como el análisis de los procesos de transformación social y de los problemas sociales.

En Galicia, existe una Comisión Interdepartamental de Información y Evaluación que determinará los planes que deben ser objeto de evaluación externa y a la que se remitirán las evaluaciones. Se ha creado recientemente el Instituto de Economía Pública de Galicia, al que se le atribuirán algunas funciones de evaluación. En Andalucía, el Instituto Andaluz de Administración Pública proporciona servicios vinculados a la evaluación, por ejemplo, análisis de la evaluabilidad de los planes estratégicos, evaluaciones ex ante, labores de difusión, una red corporativa de evaluadores y varias guías. Fruto de la evaluación realizada por AIReF, Castilla y León ha anunciado la intención de crear una Agencia Autonómica de Evaluación Independiente de las Políticas Públicas y la Calidad de los Servicios adscrita a su Consejo de Cuentas.

Numerosas CC. AA. disponen en sus organigramas de unidades responsables de la evaluación de políticas de diferentes sectores. Por ejemplo, en el caso de Extremadura, a la Dirección General de Planificación y Evaluación de las Políticas Activas del Servicio Extremeño de Políticas de Empleo le corresponde la planificación y evaluación de las políticas activas de empleo. En la Comunidad de Madrid puede encontrase un Área de Evaluación de Políticas Activas y Estrategia de Empleo en la Consejería de Empleo, así como varias subdirecciones generales de evaluación en consejerías sectoriales, como en educación o en políticas sociales. En algunas CC. AA. existen agencias de evaluación de la educación, como la Agència Valenciana d'Avaluació i Prospectiva o la Agència de Gestió d'Ajusts Universitaris i de Recerca en Cataluña. En otras CC. AA., como el Principado de Asturias y Cantabria, las evaluaciones disponibles están vinculadas a servicios o programas concretos, como los servicios sociales o los programas de género. En La Rioja, la Consejería de Hacienda incluye en su organigrama un Servicio de Evaluación de Políticas. 
En 2018, Aragón constituyó la Comisión para la Evaluación de las Políticas Públicas y la Calidad de los Servicios Públicos. En las Islas Baleares se prevé la creación de una Oficina de Evaluación Pública, que está dando los primeros pasos. En el caso de Canarias, dentro de la Estrategia para la Modernización y Mejora de los Servicios Públicos (PEMAC 2012-2014), se desarrollaron diferentes acciones formativas.

En Castilla-La Mancha se ha anunciado la creación de un nuevo órgano propio de fiscalización externa de las finanzas públicas (la Sindicatura de Cuentas se suprimió en 2014), que tiene previsto realizar tareas de fiscalización, analizando la utilización de recursos y «atendiendo al grado de cumplimiento de los objetivos programados», según reza el Anteproyecto de Ley de la Cámara de Cuentas de Castilla-La Mancha.

\subsubsection{Capacidad evaluadora y cultura de evaluación}

Tres análisis recientes de CC. AA. específicas llegan a conclusiones similares, que probablemente podrían ser compartidas por la mayoría de ellas. Los tres trabajos prueban que en las CC. AA. existen conocimientos y concienciación sobre la utilidad de la evaluación, pero falta reforzar la formación de los empleados públicos, los sistemas de información y el uso de los datos.

En Murcia, y dentro del marco de la Estrategia Regional de Gobernanza Pública, se constituyó un grupo de trabajo sobre EVPP, que en 2020 presentó un diagnóstico de la EVPP en la región con resultados interesantes sobre la capacidad de evaluación (carencia de recursos, ausencia de metodología y estructura organizativa adecuada, falta de interés, entre otros) y la necesidad de reforzarla ${ }^{18}$.

En un estudio sobre la EVPP en la Comunidad Valenciana, se identifican numerosas prácticas de evaluación en la Generalitat e incluso diferentes fases del proceso de institucionalización según la consejería o el organismo (Barberà, Doria, NtutumuSanchis \& Sanchis, 2020). Destaca el arraigo de la evaluación en los casos de la Agencia Valenciana d'Avaluació i Prospectiva o en el área de cooperación al desarrollo. Además, en la propia Consellería de Presidencia se encuentra la Dirección General de Análisis de Políticas Públicas. Existen numerosas guías, pero no un enfoque único de evaluación para toda la Administración autonómica. Se detectan también importantes necesidades de mejora, especialmente, en la capacidad evaluadora.

AIReF (2021) ha estudiado recientemente el caso de Castilla y León, concluyendo que en esta comunidad podría implementarse una estructura para la EVPP aprovechando la experiencia de los organismos ya existentes y con escasas modificaciones legales. Sin embargo, también concluyó que es necesario reforzar elementos clave de la capacidad, en particular los sistemas de información y el uso de datos y la formación de los empleados públicos.

\footnotetext{
18 https://ransparencia.carm.es/wres/transparencia/doc/Organos-colegiados/Grupo_de_trabajo_Eval_ pol_pub/2020_12_03/Mapa_Diagnostico_Calidad_Evaluacion_y_Planificaci\%C3\%B3n_CARM.pdf
} 
En esta comunidad, un $66 \%$ de los responsables públicos entrevistados indica que los planes y programas incorporan indicadores de actividad o de implementación, pero solo la mitad de los entrevistados afirman que disponen de indicadores de impacto. El tratamiento informático de los datos también es limitado (menos del $40 \%$ señalan que esto se haga muy a menudo o a menudo). Solo un $25 \%$ afirma que explota los datos muy a menudo o a menudo y el cruce entre datos en diferentes consejerías de la propia Junta es infrecuente (solo un $12 \%$ reconoce que esto se hace muy a menudo o a menudo). No existe una plataforma de datos donde se posibilite el acceso fácil, ágil y seguro en términos de confidencialidad por parte de la propia Administración autonómica a la información de las distintas consejerías.

En cuanto a las necesidades formativas vinculadas a las tareas de evaluación, al menos un $40 \%$ de los responsables públicos asegura que sus equipos han tenido que realizar muy a menudo o a menudo tareas como diseñar indicadores de seguimiento e impacto, realizar informes de seguimiento de la implementación y el impacto de los programas o diseñar algún tipo de evaluación. Pero, al mismo tiempo, reconocen que, para muchas de estas tareas que los empleados públicos ya realizan, no cuentan con la formación adecuada. La Figura 3 muestra que, en general, a medida que las tareas que toda evaluación implica se van sofisticando, los responsables públicos creen que su equipo requiere un apoyo formativo mayor. Por ejemplo, alrededor de un $80 \%$ del personal necesitaría formación para poder establecer indicadores de implementación e impacto de los programas. El uso de metodología cualitativa y, especialmente, de metodología cuantitativa y experimental supone otra necesidad para los trabajadores respecto a la cual alrededor del $90 \%$ de los responsables públicos identifican que se requiere mayor formación.

A pesar de que el $98 \%$ de los responsables públicos entrevistados creen que la evaluación es una fuente de información para el diseño de políticas, un elevado $85 \%$ afirma utilizar muy a menudo o a menudo la intuición, y menos de un $35 \%$ utiliza alguna fuente de conocimiento externo al programa.

Otros objetivos de la evaluación para los entrevistados son: rendir cuentas a la ciudadanía $(95 \%)$, el aprendizaje organizativo $(90 \%)$ y la eficiencia en el gasto (86\%), ayudar para tomar decisiones políticamente delicadas $(72 \%)$ y entender las necesidades de la ciudadanía (71\%). Además, creen que debe dársele más importancia a la EVPP en sus consejerías. Utilizando una escala de 0 a 10, consideran que la importancia que tiene la evaluación supera por poco el aprobado $(5,4)$ y creen que debería alcanzar al menos el 8,2.

Para acabar este repaso de las Administraciones autonómicas, cabe destacar la participación de las CC. AA. en el IV Plan de Gobierno Abierto de España 20202024, elaborado por la Administración General del Estado, las propias Administraciones regionales y la FEMP. Este plan se compromete a avanzar en la gestión de datos en abierto, lo que es importante para la EVPP. Además, algunas instituciones de control externo autonómicas han reforzado la formación de su personal y han realizado, junto a sus habituales auditorías de gestión u operativas, algunas evaluaciones. 

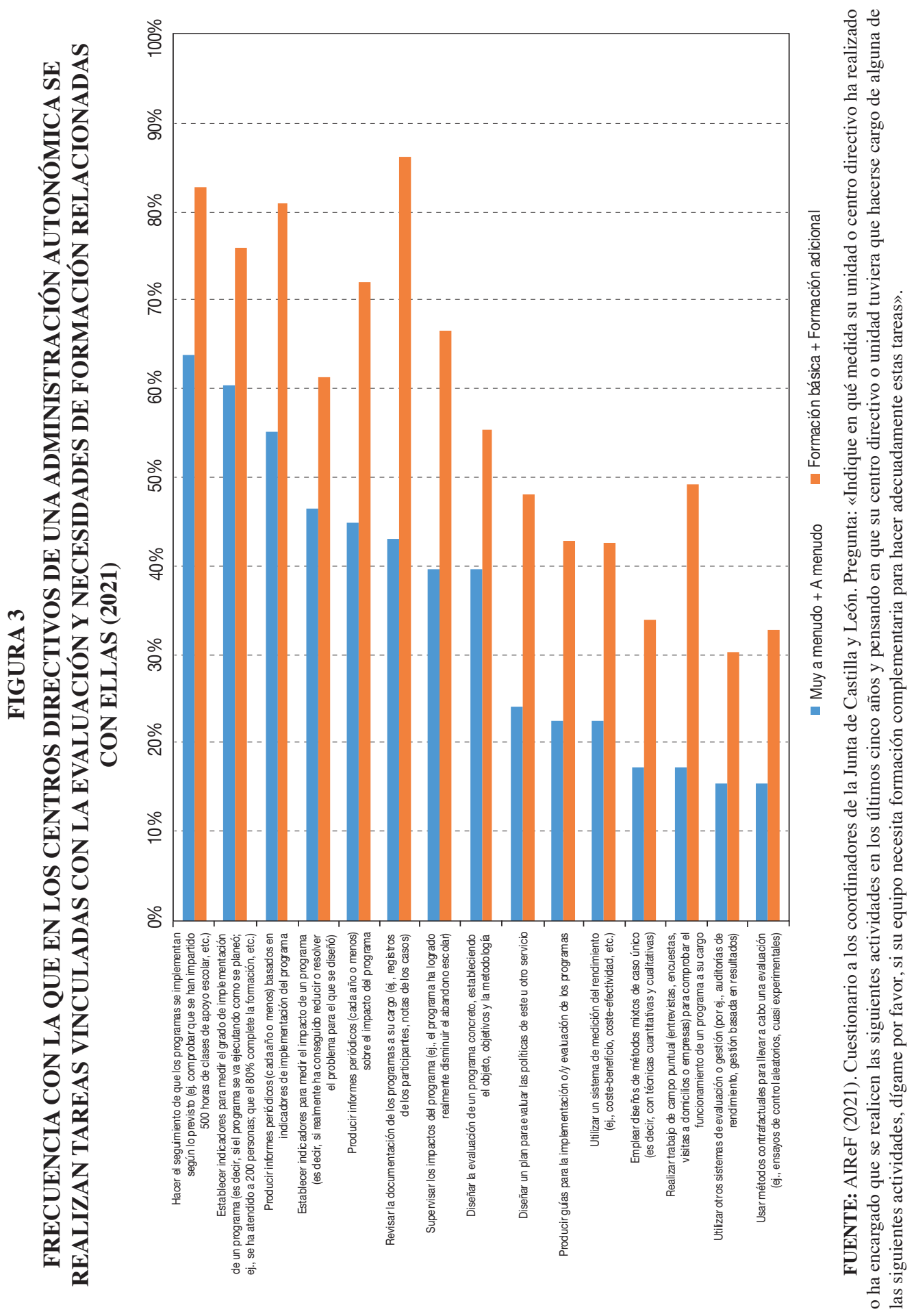


\subsubsection{La actividad evaluadora y la trascendencia de las evaluaciones}

Como ocurría en el caso de la Administración General del Estado, es difícil identificar las evaluaciones que se llevan cabo en las CC. AA., salvo cuando cuentan con una institución de evaluación. En el caso de Cataluña, Ivàlua recoge en su página web sus informes de evaluación y lo que llama informes de revisión de la evidencia $^{19}$. El Observatorio de la Realidad Social de Políticas de Navarra tiene también disponibles algunos estudios.

Aunque las CC. AA. no cuentan con instituciones de evaluación propias, en ocasiones encargan a terceros estos ejercicios. Hay que recordar que ocho CC. AA. (Cantabria, Cataluña, Andalucía, Castilla y León, Aragón, Extremadura, la Comunidad Valenciana y Navarra) han realizado varios encargos de evaluación a la AIReF, cada una de ellas en diversos sectores de política pública.

Asimismo, la mayoría de las CC. AA. disponen de guías de evaluación generales (sobre diseño de la evaluación o distintos tipos de evaluación) o sectoriales (por ejemplo, de evaluación de políticas sociales o de género, entre otros). Ivàlua cuenta con una gran variedad de ellas. El caso más reciente es el de Murcia que, en 2021, ha presentado la Guía de Evaluación de Planes, Programas, Estrategias y Servicios Públicos, elaborada en colaboración con la Universidad de Murcia.

En cuanto a la trascendencia de la evaluación, puede ser de interés la reciente innovación del caso de Cataluña, quien en su normativa de 2020 (mencionada anteriormente) se refiere de manera específica a lo que denomina revisiones de gasto que tienen «por objeto detectar ganancias de eficiencia y eficacia en la gestión de los recursos públicos para maximizar el impacto social del gasto público». En este caso, el departamento competente en materia de economía y finanzas realizará este proceso de revisión del gasto, en colaboración con el resto de los departamentos y entidades del sector público de la Generalitat.

\section{Discusión y conclusiones}

En este artículo se ha repasado en qué medida se encuentran en España los elementos que están presentes en los sistemas de evaluación de otros países que han avanzado más en el proceso de institucionalización. Se ha revisado hasta qué punto existe un marco normativo y organizativo que ampare la evaluación, se dispone de capacidad evaluadora y pueden encontrarse entre los responsables públicos actitudes y valores afines a la evaluación (una cultura de evaluación), y si se practican y utilizan las evaluaciones. En este epígrafe, se recapitulan los hallazgos y se discute si estos elementos logran garantizar los principios de independencia, investigación sistemática, profesionalidad y relevancia, que la literatura sobre institucionalización

19 https://ivalua.cat/es/node/31 
de evaluación considera esenciales para el buen funcionamiento de los sistemas de EVPP.

La primera conclusión es que los mencionados elementos están presentes de una u otra manera en España. La estructura institucional de evaluación está compuesta por la AIReF, configurándose como el principal agente evaluador en los últimos años, el IEPP y otros organismos públicos y agentes privados que practican la evaluación de políticas de una forma más o menos sistemática. También algunas CC. AA. cuentan con entes dedicados a la evaluación y/o encargan evaluaciones a otras entidades como AIReF. En relación con el marco normativo, no existe una ley de evaluación, rasgo que se comparte con otros países, incluso con algunos en los que la EVPP es una actividad con cierta tradición, como Canadá o Reino Unido (OCDE, 2021), aunque se ha abierto una consulta pública sobre el tema. En el caso de AIReF, las reglas de sus evaluaciones se establecen en los acuerdos (planes de acción) que se firman en el contexto de cada encargo que AIReF recibe por parte de los Gobiernos. Aunque no hay normativa que asegure las evaluaciones, como hemos visto, la AIReF ya ha recibido tres encargos de evaluación del Gobierno central y ocho de las CC. AA., cada uno de los cuales implica varias evaluaciones, y existe el compromiso de continuar realizando encargos hasta el 2026 (SR 2022-2026, Componente 29 del PRTR). Además, en el nivel central de gobierno también existen algunos planes sectoriales de evaluación que parecen haberse consolidado.

Cierta formalización legal es necesaria, en particular para intentar garantizar la continuidad y calendarizar mejor los encargos de evaluación, así como para aclarar el papel de los organismos implicados, por ejemplo, a la hora de decidir quién puede proponer qué políticas deben ser evaluadas. Sin embargo, como demostró la experiencia de la AEVAL, el despliegue normativo no es suficiente. Además, una reciente evaluación de la AIReF sobre la institucionalización de la EVPP en Castilla y León ha encontrado numerosas previsiones normativas que permiten e incluso obligan a poner en marcha un sistema de evaluación. Sin embargo, en muchas ocasiones las normas no se han implementado y los sistemas no están funcionando.

En España, la evaluación es una práctica relativamente reciente impulsada en nuestro caso por la pertenencia europea, tanto en sus primeros pasos como en sus más recientes avances, en particular en el caso de la AIReF (también de origen y fuerte vinculación europeísta). Como también hemos visto en el repaso del caso español, la consolidación del sistema requiere, sin duda, del apoyo político y, en particular, este apoyo debe, paradójicamente, garantizar que los evaluadores gozarán de independencia respecto de aquellos que tienen que garantizársela.

En ocasiones se ha discutido la conveniencia de vincular las agencias evaluadoras al Parlamento para garantizar su independencia. Sin embargo, esta es una opción que también presenta inconvenientes (como la lejanía respecto de la Administración evaluada, los escasos recursos con los que cuentan algunos parlamentos y la escasa formación en materia de análisis de políticas públicas de gran parte de su staff). La supuesta ventaja que tendría la vinculación al Parlamento puede garantizarse y, de hecho, se garantiza en diferentes países de otros modos. En el caso de la AIReF, 
el sistema de elección de su presidenta por mayoría absoluta del Parlamento, su origen y vinculación con Europa, su sistema de financiación y el encargo de los SR separados del ciclo político contribuyen a garantizar el principio de independencia. Aunque AIReF no puede, por el momento, decidir sobre las evaluaciones que desea hacer, en la práctica y en la actualidad, hay que reconocer el gran interés que los Gobiernos están mostrando en evaluar sus programas y políticas. Por otro lado, la experiencia demuestra que la petición voluntaria de los Gobiernos para que sus políticas sean evaluadas facilita la consecución de datos, la constitución de equipos mixtos compuestos por evaluados y evaluadores y el aprendizaje, que no solo se produce alrededor del resultado de las evaluaciones, sino también a lo largo del proceso. Igualmente, es de esperar que cuando las Administraciones solicitan evaluaciones sean más proclives a aceptar las propuestas de cambio o reforma.

Otro elemento imprescindible para la institucionalización y que también depende en gran medida de la voluntad política es la difícil construcción de la capacidad evaluadora que garantice el principio de profesionalidad e investigación sistemática. La EVPP requiere de una política de evaluación que tenga continuidad en el tiempo (frente a intervenciones esporádicas), es decir, de un presupuesto propio y herramientas como tecnologías, datos y sistemas de información, que van mejorándose progresivamente. Como ya se ha explicado, tanto en el nivel central de gobierno como en las Administraciones autonómicas este asunto sigue presentando un amplio margen de mejora.

En particular, tanto si las Administraciones hacen evaluación como si pretenden solo gestionar encargos que hagan a terceros, es necesario un personal que disponga de habilidades y de un elevado nivel de cualificación interdisciplinar, que requiere, además, estar en continuo aprendizaje debido a que las tecnologías, las metodologías y los enfoques cambian continuamente (Vedung, 2010). El análisis de una comunidad autónoma ha detectado importantes necesidades de formación básica y especializada en evaluación, que probablemente serán similares a las de muchas otras CC. AA. y ministerios.

Respecto a la cultura evaluadora, los responsables públicos entienden la utilidad de la evaluación, pero es necesario que los gestores públicos comprueben las ventajas de contar con la evidencia en las decisiones de política pública (y el menor protagonismo que tiene que tener la intuición) y se entienda que la evaluación implica estimar el impacto de las intervenciones públicas en los problemas sociales de forma objetiva, y si existe una forma más eficaz y eficiente de resolver estos, y no solo en evaluar la legalidad del gasto o si las políticas se están implementando como estaba previsto.

Por último, disponer de una herramienta que reuniese todos los ejercicios de evaluación y el alcance y trayectoria de sus recomendaciones permitiría también gestionar el conocimiento producido, y que las Administraciones y otros actores pudieran intercambiar una valiosa información para el diseño de programas públicos. La AIReF tiene ya programada la puesta en marcha de un observatorio que recoja y sistematice el resultado de sus propias evaluaciones y el seguimiento de las propuestas que realiza a cada Administración. El reciente PRTR y el propio Ministerio de 
Hacienda han aprobado algunas medidas para asegurar el uso de las evaluaciones de AIReF en el proceso presupuestario. Sin embargo, asegurar el principio de cumplir o explicar es el gran reto pendiente. Como ya se ha explicado, de acuerdo con este principio los centros directivos cuyas políticas se han evaluado tienen o bien que incorporar los resultados de la evaluación al rediseño de sus políticas o bien, si no los incorporan, deben explicar por qué no lo hacen. Junto a las medidas que se acaban de mencionar, para garantizar este principio es necesario avanzar en otras como la publicación incondicional de los informes de evaluación y su debida difusión en la sociedad civil y, en particular, entre los parlamentarios.

Para acabar, como hemos experimentado en España, la institucionalización de la EVPP es un proceso a menudo tortuoso, con frecuentes avances y retrocesos. En los dos análisis internacionales que se han presentado en este artículo, la institucionalización del sistema de evaluación español se ubicaba en una posición intermedia. Ninguno de los dos análisis incluye los recientes avances en materia de evaluación que España ha experimentado en los últimos años, en particular el surgimiento y refuerzo de la AIReF en el terreno de la evaluación de políticas y los avances en las CC. AA.

Con todo, a pesar de que al incluirse estos recientes avances es posible que la posición de España mejore en los rankings internacionales sobre la institucionalización de evaluación de políticas, precisamente por lo difícil que en nuestro país está resultando la consolidación del sistema de evaluación, se hace necesario no caer en la complacencia y continuar trabajando para seguir avanzando con un enfoque realista, pragmático y posibilista que dé respuesta a los retos que se han mencionado en este artículo.

\section{Referencias bibliográficas}

AEVAL, Agencia Estatal de Evaluación de las Políticas Públicas y Calidad de los Servicios. (2018). Informe General de Actuación de AEVAL 2016. Ministerio de Hacienda. http://www.aeval.es/export/sites/aeval/comun/pdf/agencia/Informe_general_ actividad_2016_AEVAL.pdf

AIReF, Autoridad Independiente de Responsabilidad Fiscal. (2021). La institucionalización de la evaluación de Políticas Públicas en Castilla y León: Situación actual y propuestas. https://www.airef.es/wp-content/uploads/2021/10/ESTUDIOS/PDF-WEB-accesibleCASTILLA-Y-LEON-1.pdf

Almunia, M., \& Rey-Biel, P. (2020). Por un cambio de cultura en la gestión de los datos en España: Una propuesta de reforma. EsadeECPol, Center for Economic Policy \& Political Economy, Insight \#17.

Banco Mundial. (2019). World Bank Group Evaluation Principles. https://ieg.worldbankgroup.org/sites/default/files/Data/reports/WorldBankEvaluation Principles.pdf

Barberà, O., Doria, E., Ntutumu-Sanchis, F., \& Sanchis, P. (2020). La institucionalización de la Evaluación de Políticas Públicas. La Comunitat Valenciana en perspectiva compara$d a$. Universidat de València.

Bustelo, M. (2020). Spain. In R. Stockmann, W. Meyer, \& L. Taube (Eds.), The Institutionalisation of Evaluation in Europe (pp. 303-328). Palgrave Macmillan. 
CEPAL. (2021). Evaluación de programas públicos. Serie Gestión Pública 87. https://repositorio.cepal.org/bitstream/handle/11362/46795/1/S2100039_es.pdf

De la Rica, S. (2020, 17 de octubre). La evaluación de las políticas públicas en el siglo XXI. El País. https://elpais.com/economia/2020-10-17/la-evaluacion-de-las-politicas-publicas-en-elsiglo-xxi.html

Del Pino, E., \& Colino, C. (2021). ¿Qué sabemos sobre cómo reformar la administración?: contenidos, capacidad y trayectorias. In E. Del Pino, \& J. Subirats (Eds.), Repensando la Administración ante los Nuevos Riesgos Sociales y Globales (pp. 69-100). INAP.

De Peuter, B., \& Pattyn, V. (2009). Evaluation capacity: enabler or exponent of evaluation culture? In A., Fouquet, \& L., Méasson (Eds.), L'évaluation des politiques publiques en Europe: Cultures et Futurs // Policy and programme evaluation in Europe: Cultures and Prospects (pp. 133-142). Editions L'Harmattan.

Eurosocial. (2015). Manual de buenas prácticas en la sistematización de la evaluación de políticas públicas. Experiencias de América latina. Documento de trabajo n. ${ }^{\circ} 29$.

FEDEA, Fundación de Estudios de Economía Aplicada. (2021). La evaluación de políticas públicas en España: antecedentes, situación actual y propuestas para una reforma. FEDEA Policy Papers 2021/09.

https://documentos.fedea.net/pubs/fpp/2021/10/FPP2021-09.pdf?utm_source= wordpress\&utm_medium=portada\&utm_campaign=estudio

Feinstein, O., \& Zapico-Goñi, E. (2010). Evaluation of Government Performance and Public Policies in Spain (ECD Working Papers Series No. 22). The World Bank. Independent Evaluation Group.

Furubo, J., Rist, R., \& Sandahl, R. (Eds.). (2002). International Atlas of Evaluation. Transaction Publishers.

Garde-Roca, J.A. (2006). La institucionalización de la evaluación de las políticas públicas en España. Auditoria Pública, 39, 17-26.

Garde-Roca, J. A. (2017, 5 de Agosto). AEVAL y su muerte anunciada. Cinco Días. El País. https://cincodias.elpais.com/cincodias/2017/08/04/midinero/1501857354_174399.html

Gobierno de España. (2021a). Plan de Recuperación, Transformación y Resiliencia. https://www.lamoncloa.gob.es/temas/fondos-recuperacion/Documents/30042021-Plan_ Recuperacion_\%20Transformacion_\%20Resiliencia.pdf

Gobierno de España. (2021b). Plan de Recuperación, Transformación y Resiliencia. Componente 29. Mejora de la eficacia del gasto público. https://www.lamoncloa.gob.es/temas/fondos-recuperacion/Documents/16062021Componente29.pdf

Gudiño, F. M. (2015). Evaluación y aprendizaje en la cooperación para el desarrollo: un análisis del caso español [tesis doctoral, Universidad Complutense de Madrid]. https://eprints.ucm.es/id/eprint/34477/1/T36737.pdf

Herrero, C. (2021). Gestión de recursos públicos y evaluación: un binomio inseparable. Boletín Económico de ICE, 3135, 23-35.

Instituto para la Evaluación de Políticas Públicas. (2021). Estudio de Diagnóstico de la Evaluación de Políticas Públicas en la Administración General del Estado. https://www.mptfp.gob.es/dam/es/portal/funcionpublica/evaluacion-politicas-publicas/Informes-de-Evaluacion/DIAGNOSTICO-EVALUACION-AGE/ESTUDIO_ DIAGNOSTICO_EVA_AGE.pdf.pdf 
Jacob, S., Speer, S., \& Furubo, J. E. (2015). The institutionalization of evaluation matters: Updating the International Atlas of Evaluation 10 years later. Evaluation, 21(1), 6-31. https://doi.org/10.1177/1356389014564248

Lázaro, B. (2015). Comparative study on the institutionalisation of evaluation in Europe and Latin America. Eurosocial Studies No. 15.

Meyer, W., Stockmann, R., \& Taube, L. (2020). The Institutionalization of Evaluation. Theoretical Background, Analytical Concept and Methods. In R. Stockmann, W. Meyer \& L. Taube (Eds.), The Institutionalisation of Evaluation in Europe (pp. 3-33). Palgrave Macmillan.

Munárriz, Á. (2020, 20 de septiembre). ¿Quién controla que las políticas sirven de algo? La falta de evaluación dispara el riesgo de una reconstrucción a ciegas. Infolibre. https://www.infolibre.es/noticias/politica/2020/09/18/quien_controla_que_politica_ sirven_algo_falta_evaluacion_dispara_riesgo_una_reconstruccion_ciegas_111143_ 1012.html

OCDE. (2021). Evaluation frameworks and practices: a comparative analysis of five OECD countries.

Pattyn, V. (2012). Why organisations (do not) evaluate. A search for necessary and sufficient conditions (COMPASSS Working Paper No. 2012-70).

Pollitt, C., \& Bouckaert, G. (2017). Public Management Reform. A Comparative Analysis into the Age of Austerity. Oxford University Press.

Rist, R. C., Boily, M. H., \& Martin, F. (2011). Influencing Change: Building Evaluation Capacity to Strengthen Governance. World Bank. https://openknowledge.worldbank.org/handle/10986/2285

Rosenstein, B. (2015). Status of national evaluation policies global mapping report (2. ${ }^{a}$ edición). Parliamentarians Forum on Development Evaluation in South Asia and EvalPartners.

https://globalparliamentarianforum.files.wordpress.com/2016/02/the-status-ofevaluation-policies.pdf

Rossi, P. H., Freeman, H. E., \& Lipsey, M. W. (2003). Evaluation: A Systematic Approach. Seventh Edition. Sage Publications, Inc.

Ruiz, A. (2012). Panorámica actual de la evaluación de las políticas públicas. Presupuesto y Gasto Público, 68, 13-23.

Stockmann, R., Meyer, W., \& Taube, L. (Eds). (2020a). The Institutionalisation of Evaluation in Europe. Palgrave Macmillan.

Stockmann, R., Meyer, W., \& Taube, L. (2020b). The Institutionalisation of Evaluation in Europe: A Synthesis. In R. Stockmann, W. Meyer, \& L. Taube (Eds.), The Institutionalisation of Evaluation in Europe (pp. 483-521). Palgrave Macmillan.

Stufflebeam, D. L., \& Shinkfield, A. J. (1995). Evaluación sistemática: Guía teórica y práctica. España: Centro de Publicaciones del Ministerio de Educación y Ciencia. Ediciones Paidós Ibérica.

Unión Europea. (2007). Developing Evaluation Capacity. https://ec.europa.eu/regional_policy/sources/docgener/evaluation/pdf/report_ integrated_2007.pdf

Vedung, E. (2010). Four waves of evaluation diffusion. Evaluation, 16(3), 263-277. 